\title{
La Maracuya o Parchita en Florida ${ }^{1}$
}

\author{
Robert J. Knight, Jr. , Julian W. Sauls, Carlos F. Balerdi y Jonathan H. Crane ${ }^{2}$
}

Nombre Científico: Passiflora edulis Sims (maracuyá púrpura); P. edulis f. flavicarpa Deg. (maracuyá amarilla); P. quadrangularis L. (granadilla gigante).

Nombre Común: maracuyá, parchita, parcha, chinola, granadilla, pasionaria, fruta de la pasión, passionfruit (inglés).

Familia: Passifloraceae.

Especies Relacionadas: Varias especies ornamentales de Passiflora están disponibles en Florida, pero no deben confundirse con las tres enredaderas productoras de frutos. Ordinariamente, estas enredaderas ornamentales no producen frutos y comprenden a la Pasionaria Roja, Passiflora coccinea Aub1. y dos híbridos P.alato-caerulea (a veces llamados P.pfordtii) y la Pasionaria Incienso (P.incarnata L. x P. cincinnata Masters). Los híbridos producen flores espectaculares de color azul y malva, respectivamente. De esta forma, el color de las flores diferencia a estas enredaderas ornamentales de las frutales, que poseen un color blanco pálido o marrón en forma de lámpara.

Passiflora incarnata L., la maracuyá silvestre, es una especie silvestre nativa de la región comprendida entre el centro de Florida y Pensylvania por el norte y el sur de Illinois, Missouri y Kansas por el oeste. Esta enredadera produce un fruto pequeño pero comestible

Origen: Regiones tropicales de América.

Distribución: Ha sido introducida y cultivada en la mayoría de las regiones tropicales y subtropicales del planeta y posee inportancia comercial en Australia, Hawaii, Africa del Sur y Brasil.

\section{Descripción}

\section{Planta}

Es una enredadera vigorosa. Tanto la maracuyá amarilla como la púrpura poseen hojas trilobuladas de 4-7" $(10-18 \mathrm{~cm})$ de longitud con márgenes finamente serrados. La granadilla gigante posee hojas redondeadasde 4-8" $(10-20 \mathrm{~cm})$ de longitud y su tallo es característicamente cuadrado cuando se corta transversalmente.

1. Este documento, HS1045, es uno de una serie de publicaciones del Departamento de Horticultural Sciences, Servicio de Extensión Cooperativa de la Florida, Instituto de Alimentos y Ciencias Agrícolas, Universidad de la Florida. (UF/IUFAS). Fecha de primera publicación: 1994. Repasado November 9, 2005. Por favor visite nuestro sitio web EDIS en <http://edis.ifas.ufl.edu> or http://fruitscapes.ifas.ufl.edu.

2. El Dr. R.J. Knight, Jr., es Profesor, Ciencias Horticolas; el Dr. J.W. Sauls fue Horticultuor de Servicio de Extension, Horticultural Sciences Department; C.F. Balerdi, Prof., Florida Cooperative Extension Service; J.H. Crane, Prof., Tropical Research and Education Center; Institute of Food and Agricultural Sciences, University of Florida, Gainesville, Florida 32611.

Taducido al Espanol en octubre del 2004 por Ruben Regalado y C.F. Balerdi, Miami-Dade County Cooperative Extension Service, Homestead, Florida.

El Instituto de Alimentos y Ciencias Agrícolas es un empleador que opera bajo Acción Afirmativa y provee Oportunidades Igualitarias, autorizado a proveer investigación, información educativa y otros servicios, únicamente a los individuos e instituciones que operan sin discriminación alguna con relación al credo, color, religión, edad, incapacidad, sexo, orientación sexual, estado civil, nacionalidad, opinion política o afiliaciones. Para más información sobre como obtener otras publicaciones de extensión, comuníquese con la oficina de Servicio de Extensión de su condado. Servicio de Extensión de la Florida / Instituto de Alimentos y Ciencias Agrícolas / Universidad de la Florida / Larry Arrington, Decano. 
La granadilla gigante produce un fruto irregularmente redondeado $\mathrm{u}$ oblongo que posee una longitud de 4-8" (10-20 cm) y tiene, además de las semillas rodeadas de jugo, una pulpa gruesa comestible. Puede alcanzar un peso de $8-16 \mathrm{oz}$ (225-450 g) o más.

\section{Flores}

Las flores de la maracuyá púrpura tienen normalmente un diámetro más pequeño que las de la amarilla, alrededor de $1.75 "(4.5 \mathrm{~cm})$ y 2.5 " (6 $\mathrm{cm})$, respectivamente. Ambas tienen un color blanco pálido con centros de color azul intenso. Las flores de la granadilla gigante son completamente diferentes; se disponen como las pantallas de lámparas antiguas y sus pétalos son de color marrón intenso en la superficie interna.

Estación de fructificación. La maracuyá púrpura florece a principios de la primavera en Florida; sus frutos maduran de 60 a 80 días más tarde, por lo que los mismos se pueden esperar a finales de mayo hasta principios de julio. La maracuyá amarilla florece desde la primavera hasta finales del otoño, con un período de reposo a principios del verano, por lo que los frutos maduros aparecen a intervalos desde inicio del verano hasta el invierno. La granadilla gigante comienza su floración en la primavera y sus frutos maduran en el verano. Puede continuar floreciendo a través de todo el verano pero comúnmente no produce frutos en esa estación en Florida probablemente debido a que las altas temperaturas interfieren con la fertilización normal después de la polinización. Cuando el tiempo se torna más fresco, la granadilla reanuda la producción de frutos que maduran fuera de estación.

\section{Fruta}

El fruto de la maracuyá púrpura tiene forma redondeada u oval y posee semillas púrpura oscuro o casi negras. Pesa $30 \mathrm{~g}$ (1-1.5 oz). El fruto de la maracuyá amarilla tiene un color amarillo intenso y de forma similar al de la púrpura pero es ligeramente más largo, $2.5 "(6 \mathrm{~cm})$. Puede alcanzar un peso de 2-3 oz (60-90 g), pero la media en las condiciones de Florida es alrededor de $2.5 \mathrm{oz}(75 \mathrm{~g})$. Los frutos contienen numerosas semillas pequeñas en forma de cuña que están rodeadas individualmente de unos saquitos (arilos) de color naranja oscuro que contienen el jugo, la parte comestible del fruto.

\section{Polinización}

La polinización es esencial para obtener una buena fructificación de la maracuyá. Las flores de la maracuyá púrpura normalmente producen frutos cuando se autopolinizan pero muchas de las amarillas no fructifican a menos que las flores sean manualmente polinizadas con el polen de una enredadera diferente que sea genéticamente compatible. Por esto, dos plantas que se hayan producido de estacas tomadas de la misma enredadera no pueden polinizarse entre ellas. Además, algunas enredaderas obtenidas de semillas pueden polinizarse de forma cruzada con otras plantas del mismo grupo pero en otros casos no. Esto debe aprenderse mediante un proceso de análisis de ensayos y errores a medida que las plantas se desarrollen.

Ordinariamente existen muchas oportunidades de polinización cruzada en una población grande de plantas obtenidas por semillas.

El insecto más efectivo para la polinización de la maracuyá es la abeja carpintera (Apidae, subfamilia Anthophoridae), una abeja solitaria grande que se asemeja a los abejorros. Las poblaciones nativas de esta abeja pueden asegurar una polinización adecuada en áreas donde la maracuyá silvestre fructifica naturalmente. En otros sitios, se deben utilizar otros medios. Puede estimularse el desarrollo de poblaciones de las abejas carpinteras colocando troncos huecos en los campos cerca de las enredaderas. Las abejas domésticas son menos efectivas debido a su pequeño tamaño y también porque prefieren colectar de otras flores en el momento en que la maracuyá está florecida. Bajo ciertas condiciones, pueden tener mayor éxito con las flores de maracuyá púrpura que son relativamente más pequeñas y autocompatibles.

La granadilla gigante también necesita polinización para asegurar la fructificación. Requiere temperaturas más frescas para la fructificación normal; puede florecer pero no cuajar o producir frutos malformados durante la temporada más cálida. La polinización manual puede ser la 
forma más fácil para asegurar la fructificación en enredaderas que crecen en patios.

\section{Variedades}

No hay cultivares bien establecidos disponibles en Florida por lo que las plantas comúnmente se propagan de esquejes provenientes de enredaderas con características deseables. Una forma de maracuyá amarilla que produce abundantes frutos en el sur de Florida mediante autopolinización se cultiva frecuentemente de esquejes y de plantas obtenidas de semilla. Sus frutos son menores que los de plantas con polinización cruzada. Hace algunos años se trajeron semillas de Hawaii de una selección de maracuyá amarilla que produce frutos grandes y plantas provenientes de esta fuente se cultivan ocasionalmente. Plantas de maracuyá púrpura seleccionadas localmente se propagan vegetativamente para la producción comercial.

\section{Clima}

La maracuyá amarilla y la granadilla gigante son plantas tropicales y por lo tanto tienen una distribución restringida en los sitios protegidos de la mitad sur de Florida. La maracuyá púrpura está adaptada a condiciones subtropicales y puede soportar las heladas ligeras del invierno sin sufrir daños, no tolera heladas severas. Crece bien el el área de la Bahía de Tampa y en sitios protegidos del centro de la península.

\section{Propagación}

Todos los tipos de maracuyá pueden propagarse de semillas, las cuales deben estar frescas (menos de un año) porque pierden su viabilidad rápidamente. Las semillas deben sembrarse en macetas $u$ otros recipientes que contengan suelo esteril y mantenerse en un lugar húmedo y a resguardo de la luz solar directa. Las semillas germinan normalmente en 10-20 días; las pequeñas plantitas crecen rápidamente y deben ponerse en recipientes individuales tan pronto como sea posible. Pueden transferirse al sitio de siembra permanente cuando alcancen una altura de $10-16 "(24-40 \mathrm{~cm})$.

La maracuyá púrpura en ocasiones se injerta en patrones de maracuyá amarilla para mitigar las enfermedades y nemátodos que afectan a su sistema radicular. Las plantitas de ambos tipos deben tener alrededor de 18 " $(45 \mathrm{~cm})$ de altura y un diámetro similar al de un lápiz al momento de realizar el injerto. El injerto debe tener una longitud de 3-4" $(8-10 \mathrm{~cm})$ y contener al menos dos nudos. El patrón debe cortarse a 10-12" $(25-30 \mathrm{~cm})$ por encima del suelo.

Para realizar el injerto, haga un corte longitudinal que abarque la mitad basal del tallito del injerto; haga un corte similar en el extremo del patrón. Una las dos superficies cortadas alineando el cambio y átelas firmemente con cinta de injerto. El injerto se protege con una bolsa plástica pequeña atada por debajo de la zona de contacto y se pone en un sitio sombreado y cálido por 10-14 días o hasta que la unión se consolide. En este momento, se abre un poco la bolsita para permitir la entrada de aire y más tarde se quita cuando el injerto comienza a crecer. La cinta de injerto se elimina para que no constriña al tallito en crecimiento.

Las estacas de maracuyá pueden enraizar si se mantienen en un sistema de neblina intermitente, pero deben seleccionarrse cuidadosamente de plantas saludables y en producción para evitar la transmisión de enfermedades virales.

\section{Siembra y Emparrados}

Idealmente, las enredaderas jóvenes deberían sembrarse a principios de la primavera después que el peligro de las heladas haya pasado. En Florida, las enredaderas se siembran a una distancia de $10-15 \mathrm{ft}$ (3-4.5 m) en surcos separados por 15-20 ft (4.5-6 m).

Los emparrados horizontales poseen 2-4 alambres separados a una distancia de $2 \mathrm{ft}(60 \mathrm{~cm}) \mathrm{y}$ montados en crucetas en la parte superior de cada poste. Los emparrados verticales consisten de postes pesados que no poseen crucetas sino que tienen 2-3 alambres extendidos que se fijan a los postes de arriba a abajo a una distancia de 12-16" $(30 \mathrm{~cm})$ como el alambre de púas.

El alambre de emparrado debe ser de acero galvanizado No. 9 ó 10. Los postes tienen que ser lo suficientemente fuertes para soportar el peso de las enredaderas durante toda la estación lo cual incluye 
normalmente las sacudidas provocadas por los vientos fuertes. Idealmente, deberían ser lo suficientemente largos para proveer apoyo a emparrados de $5 \mathrm{ft}(1.5 \mathrm{~m})$, con 18-30" (45-75 cm) dentro del suelo. Las líneas de emparrados deben orientarse de norte a sur para obtener la máxima exposición al sol; debe permitirse que las enredaderas crezcan juntas en los emparrados para estimular la polinización cruzada.

\section{Poda Formativa}

En la naturaleza, la enredadera de la maracuyá trepa sobre los árboles o rocas disponibles y se extiende para alcanzar la luz solar. La maracuyá amarilla se ha naturalizado de esta forma en algunas partes del sur de Florida. Cuando las enredaderas se cultivan, su crecimiento debe guiarse para que cubran los alambres de los emparrados o cercas en las cuales crecen.

Las enredaderas jóvenes se guían dirigiendo una ramita que crezca hacia arriba para que alcance la parte superior del emparrado y una vez que esté allí, permitiendo que una nueva ramita crezca a lo largo de los alambres en ambas direcciones. Un emparrado de 2 alambres proverá 4 ramitas nuevas que crecen alejándose del tronco de la enredadera. Una vez que la enredadera comience a crecer debe permitírsele crecer sin poda durante toda la estación ya que a mayor cantidad de enredadera mayor será la superficie que produce frutos. Con las formas autoimcompatibles de la maracuyá amarilla es deseable permitir que dos enredaderas diferentes, que puedan fertilizarse de forma cruzada, crezcan juntas y sus ramas se entremezclen para promover una fructificación alta.

Las enredaderas deben podarse a final del invierno cuando ellas no crecen activamente. Todas las rama muertas y débiles deben cortarse y dejar sólo las ramitas vigorosas con numerosas yemas de manera tal que pueda reanudar un crecimiento activo a inicios de la primavera. Desinfecte las tijeras de podar al terminar de podar una enredadera y comenzar con otra para evitar la transmisión de enfermedades entre plantas. Un buen momento para realizar la primera fertilización es después de la poda.
Las enredaderas son plantas perennes de vida corta. Algunas maracuyá amarillas en el sur de Florida han sobrevivido por 10 años pero esto es la excepción. Una esperanza de vida más realista es de 3-5 años. Una enredadera que parezca tener una cantidad excesiva de ramas muertas ha perdido su vigor y debe ser eliminada y reemplazada por una planta jóven y saludable.

\section{Suelos}

La enredadera prefiere los suelos ligeramente ácidos, pero la maracuyá amarilla tolera los suelos alcalinos del sur de Florida si se añaden los microelementos adecuados. Un suelo con buen drenaje es esencial pues en caso contrario, se producen problemas en las raíces que pronto destruyen a las plantas.

\section{Abonos}

Un fertilizante adecuado para la maracuyá en los suelos arenosos ligeramente ácidos característicos de Florida debe proveer nitrógeno, fósforo y potasio en proporciones aproximadamente iguales y también los micronutrientes esenciales (magnesio, manganeso, cobre, zinc y hierro). En los suelos alcalinos rocosos del sureste del estado, se necesita menos fósforo que nitrógeno y potasio, pero los micronutrientes deben aplicarse para obtener un crecimiento y producción normal. Además, soluciones de chelatos de hierro pueden aplicarse al suelo cerca de las raíces.

El fertilizante debe aplicarse a principios de la primavera antes de que comience el crecimiento. Se deben realizar aplicaciones ligeras a intervalos de 4 a 6 semanas hasta julio en la parte norteña del rango de la maracuyá y hasta octubre en la sureña. Las enredaderas consumen bastante fertilizante pero la fertilización excesiva daña a las raíces y puede destruir la planta. La cantidad a aplicar depende del tamaño de la planta y puede ser determinado por la experiencia. Nunca se deben aplicar más de 4-6 oz $(110-170 \mathrm{~g})$ de un fertilizante de análisis bajo (6-6-6, 5-7-5, etc.) de una sóla vez hasta que se haya determinado que una cantidad mayor puede aplicarse con seguridad. El fertilizante debe esparcirse uniformemente en un círculo alrededor del tallo, 
con un radio aproximado de $18 "(45 \mathrm{~cm})$; riegue la planta más tarde.

\section{Plagas}

Existen pocas plagas que ataquen al fruto de la maracuyá. Una chinche apestosa puede agujerear los frutos jóvenes pero los mismos continuan su desarrollo más o menos normalmente.

Los nemátodos y los hongos que invaden a las raíces son las plagas más comunes de las especies de Passiflora en Florida. En realidad, es imposible cultivar la maracuyá púrpura en la mayor parte del sureste de Florida a menos que esté injertada en patrones de maracuyá amarilla u otra especie resistente. Nemátodos y dos especies de hongos, Phytophthora y Fusarium, se han encontrado en las raíces de las enredaderas enfermas. La maracuyá amarilla es más resistente a los organismos dañinos del suelo que la maracuyá púrpura pero no es inmune. Las enredaderas pueden mostrar síntomas de cancro o lesiones del tallo cerca del suelo y perder su vigor lentamente después de haber crecido durante 5-7 años. Cuando esto ocurre, es aconsejable sembrar enredaderas nuevas, preferiblemente en un nuevo sitio. Los problemas con las raíces son menos comunes en las enredaderas del centro del estado que en las del extremo sur.

Enfermedades virales afectan a la producción de maracuyá en Australia. También se han descubierto en Hawaii y en un cultivar ornamental en Florida. Debido a los problemas que los virus causan a los cultivadores de papayas en Florida, se deben usar todos los métodos prácticos para proteger las plantaciones de maracuyá de posibles infecciones virales. Cualquier enredadera cuyas hojas muestren síntomas de mosaico o aclaramiento de las venas deben eliminarse y destruirse. También, las plantas deben propagarse de semillas siempre que sea posible. Las enredaderas utilizadas como fuente de estacas deben mantenerse libres de insectos en invernaderos para protegerlas de las infecciones virales.

\section{Producción y Cosecha}

Las plantas de semillas sembradas en la primavera pasan la mayor parte de la primera estación en un estado de crecimiento vegetativo vigoroso aunque pueden aparecer algunas flores y frutos al final del verano en las enredaderas de la maracuyá amarilla. Las enredaderas sembradas de estacas florecen con mayor profusión y producen más frutos en el primer año que las de semillas, pero las enredaderas obtenidas de estacas son más caras y frecuentemente menos vigorosas que las de semillas. Además, se debe ejercer gran precaución para mantener las fuentes de estacas libres de enfermedades lo cual no es necesario en el caso de las semillas.

La mejor producción que se puede esperar en Florida, hasta que cultivares más productivos sean desarrollados, es de aproximadamente 7.5-15 lbs (3.5-7 kg) de frutos por planta de la maracuyá amarilla. Con este nivel de producción y una distancia de siembra de 10 x $15 \mathrm{ft}$ ( 3 x $4.5 \mathrm{~m})$ uno podría esperar con optimismo una producción de 2,200-4,400 lb./acre (2.5-5 toneladas métricas/ha) de frutos de la maracuyá amarilla. La púrpura tendría rendimientos probablemente iguales a $1 / 3$ de esta cantidad. No existen datos suficientes para predecir los rendimientos de la granadilla gigante en Florida.

\section{Maduración y Almacenamiento}

La cosecha completa de la maracuyá púrpura y la cosecha temprana de la amarilla maduran a finales de la primavera y principios del verano. Entonces, las enredaderas crecen vegetativamente y la mayoría no florecen cuando los días son más largos, desde el 21de junio hasta el 4 de julio. Las enredaderas de la maracuyá amarilla comienzan su segunda floración en la última mitad de julio, usualmente tienen un pico a mediados de agosto y continuan hasta octubre y noviembre. La frutos de esta segunda floración maduran de septiembre hasta principios de febrero.

El fruto permanece verde hasta que alcanza la madurez con un cambio de color rápido, en sólo unos cuantos días. Tanto la maracuyá amarilla como la púrpura caen al suelo cuando maduran. Los frutos no deben recogerse antes de caer al suelo ya que colectados de las enredaderas tienen un sabor 
similar al de la madera. En algunas regiones, el suelo debajo de las enredaderas se mantiene libre de malezas y los frutos caídos se recogen de una a dos veces por semana. En Florida, los frutos se recogen fácilmente del suelo dos veces a la semana si los mapaches y otros animales no son abundantes. Los frutos del verano deben recogerse diariamente debido a las altas temperaturas y al peligro de las quemaduras de sol.

Los frutos de ambas enredaderas comienzan a perder humedad tan pronto como caen al suelo y se arrugan rápidamente si se mantienen en condiciones calientes y secas. El jugo de estos frutos mantiene su calidad pero el aspecto exterior de los mismos es desagradable y por lo tanto, pierden su valor en el mercado. Los frutos limpios pueden almacenarse en bolsas de polietileno a $50^{\circ} \mathrm{F}\left(10^{\circ} \mathrm{C}\right)$ por un período no mayor de 3 semanas sin pérdidas.

Se han usado, experimentalmente, redes de alambres montadas en marcos inclinados debajo de las enredaderas para colectar los frutos maduros que caen, ruedan y pueden recogerse más fácilmente.

El fruto de la granadilla gigante se torna dorado intenso cuando está maduro y puede recogerse en este estado para su consumo. Si estos frutos se van a embarcar, se pueden recoger tan pronto el área que rodea el tallito de los mismos comienza a tornarse amarilla.

\section{Usos y valor nutricional}

El jugo de la maracuyá es una buena fuente de ácido ascórbico (vitamina C) y carotenoides (vitamina A). Tiene un sabor rico y fuerte pero agradablemente aromático. El jugo sin diluir es altamente concentrado pero es un aditivo excelente para otros jugos o puede beberse si se le añade agua y azúcar. El jugo puede usarse para hacer jaleas, pasteles y glaseados de tortas excelentes. Las semillas con sus sacos de jugos se utilizan en las ensaladas de frutas en Australia. El fruto de la maracuyá púrpura (más dulce y menos ácido que el de la amarilla) puede comerse con semillas. El jugo de la granadilla gigante tiene un sabor más suave y se usa en bebidas y confecciones. La pulpa comestible que se asemeja a la del melón, puede pulverizarse y usarse en pasteles. 